\title{
A conversation with Barbara Kahn
}

B arbara Kahn is the quintessential physician-scientist. Dr. Kahn (Figure 1), of the Beth Israel Deaconess Medical Center and Harvard Medical School, is best known for elucidating molecular mechanisms of type 2 diabetes, obesity, and insulin resistance, with a particular emphasis on the role of the adipocyte in regulating glucose metabolism. To see the full interview, including her tales of going to Studio 54 with Andy Warhol, see the JCI website at https://jci. org/videos/cgms.

JCI: How and where were you raised?

Kahn: I grew up in an 1,800-person community called Fairway, Kansas. The land had originally belonged to Shawnee Native Americans, and there remained a reservation nearby. My parents had moved there because they had relatives in the general area, and the school systems were excellent. My parents were both born from immigrants: my father's father came from Lithuania, and my mother's father came from Latvia. My mother grew up in Michigan in a town of 200 people, where her father had the only store in town. My father grew up in Chicago, where his father had a haberdashery.

My father never went to college, but nevertheless, was very successful as a businessman. My mother graduated from college after she was married and had begun to have children, and she received a master's in social work degree while pregnant with her fourth child. My parents put a major emphasis on education, community service, and community leadership. I went to public school through the eighth grade and was very interested in math and science. One year the math teacher asked me to write the exam. The other students found out and were irate. The boys drew a picture of me as a ticker tape machine with my tongue as the tape. I knew I needed to get out of there.

I transferred to a private girls' school for high school. There were only 27 girls in my class, and it was wonderful. The teachers and the environment encour-

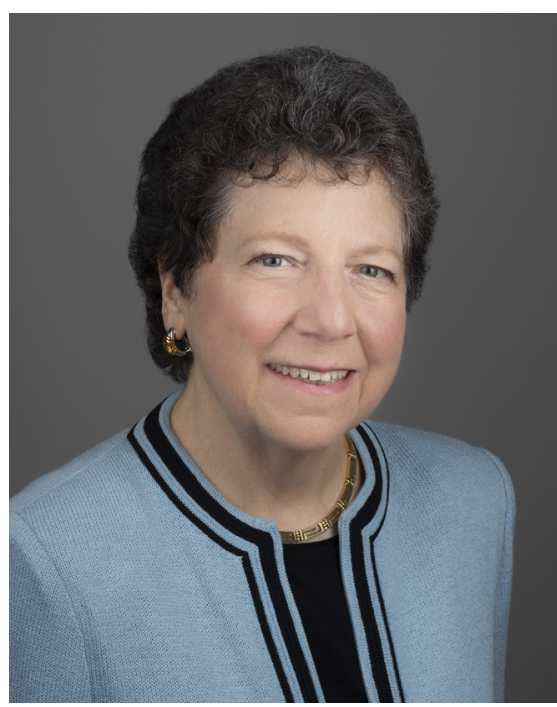

Figure 1. Barbara Kahn, August 12, 2019. Photo credit: Beth Israel Deaconess Medical Center

aged students to be involved. I danced in the operettas, sang in the glee club, played field hockey, and I was president of the senior class and the student council. The school hired a math teacher from the local junior college to teach three of us advanced algebra and calculus.

JCI: What made you decide to go to Stanford to study anthropology?

Kahn: Two students who were several years ahead of me had gone to Radcliffe. I knew Radcliffe would provide an excellent education and expand my worldview. I went to interview on a very dark wintry day. It was very intense, and the students did not seem particularly happy. Stanford seemed like a great alternative, and I also was very attracted to the progressive political atmosphere in California.

I was going to study either anthropology or astronomy. The first astronomy course I took had too much physics for me. Anthropology was fantastic, but I realized that I wanted to be able to interact more directly with people. I didn't have the notion of being a physician at that time, but just as my mother helped people as a social worker, I really wanted to help peo- ple more directly and that wasn't part of anthropology as I understood it.

JCI: When did you pivot towards a medical career?

Kahn: I went to Stanford in Italy for a semester. The campus is in Fiesole, up the hill from Florence. While I was there, we studied the culture of the lithographers that lived in the Arno River valley. Every day after class, we took the bus to Florence to see the artwork or visit the lithographers. At the bus stop, there was a phlebotomy lab. I had been diagnosed with type 1 diabetes as a teenager, and it was frustrating in those days: there was no home blood glucose monitoring or hemoglobin A1Cs, and it was very hard to know what your blood sugar was. If it wasn't an emergency, it would take days before a blood glucose order went in. And then you had to wait to talk with a nurse or a doctor to obtain the result. By the time you got it, you forgot what you'd been doing when you'd had the blood glucose drawn. But in Fiesole, I walked into this phlebotomy lab, and they said, "Sure, you're next in line." I was able to have the blood sugar drawn and to stop back the next day to get the result. That was such an eye-opening experience. I felt like medical practice could be so much more patient oriented. I was interested in how to help people with chronic illnesses, and the idea that patients could actually have more control over their medical situation was what made me think I might go to medical school. When I got back, I worked in the Berkeley Free Clinic and with the Berkeley Women's Health Collective. I wanted to see if there was another role in the health professions through which I could have a greater impact. That experience convinced me that there were many very important roles for health professionals. But I specifically wanted to have the knowledge, experience, and power that physicians had.

I started medical school in an experimental basic science program at the University of California, Berkeley, where I received a master's degree in health sciences. I transferred to Stanford University for my last two years. I had no notion at all of doing research, and I thought family 
medicine was one of the best ways to help people cope with long-term medical problems. My oldest brother also had decided to go into family medicine. This was in the 70 s in the San Francisco area. There was a lot of social change going on, and the women's movement was very important; family medicine seemed like the ideal calling.

JCI: When did you turn to endocrinology?

Kahn: I had decided I was going to avoid endocrinology because diabetes already played too large a role in my life. But I had a fabulous endocrinology rotation as a medical student under the tutelage of the legendary chief of medicine, Dan Federman. On that rotation, any question a trainee asked, Dan used to enlighten us on a point related to endocrinology. After the rotation, I was talking to him about going into family medicine and he said, "Family medicine is very important, but I think you like to understand things in more depth. I think you'd be happier in internal medicine."

In fact, I did an internal medicine residency while still thinking I would go into primary care, and at the end of the residency, there was a lot of pressure on me to do an endocrine fellowship. But I did not want to just follow along in a traditional path. At that time, a new type of fellowship emerged called general medicine fellowships, and this appealed to me because there was no job description. That was exactly what I was looking for a blank slate so I could figure out what I wanted to do.

There was one stipulation for the general medicine fellowship: you needed to do some research. I had read a couple papers out of the UK about home blood glucose monitoring. It seemed like that would be really helpful for people with diabetes because at that time all that was available was urine glucose monitoring, which wasn't very accurate. Urine monitoring was also inconvenient, as you had to have an eye dropper and put urine and water in a test tube and put a tablet in and boil it, and at a certain number of minutes, you had to read the color. But the color kept changing, and it also didn't reflect what your blood sugar was at that moment, but rather the cumulative amount of glucose since the last time the bladder was emptied. I was very attracted to the idea of home blood glucose monitoring, but there were two questions.
One, did it work? There were no randomized, controlled or cross-over studies to see if it really worked. And two, would it have adverse psychological effects? I designed a study and convinced nurse educators, dietitians, other physicians, and a statistician to work with me. We carried out a crossover study comparing blood and urine glucose monitoring and found that anybody who entered in this study improved their diabetes control. That's referred to as the study effect, i.e., receiving attention and encouragement as a participant in a clinical study can help people improve their glucose control.

Our results were different from what physicians were reporting in the UK. I decided to go to the UK to compare our results. I also had a boyfriend in the UK doing a sabbatical, so it all seemed like a perfect arrangement. During that visit, I toured diabetes research institutes and realized that diabetes did not have to be depressing: there actually was great hope for what could be accomplished with research.

JCI: Is that what brought you to NIH?

Kahn: At that time, I wasn't absolutely sure I would do an endocrine fellowship. I really wanted to understand how insulin works. Patients were responsible for juggling their calorie intake, carbohydrate intake, insulin, and exercise, and if we could understand better how insulin worked, it might help people know which type of insulin (short or long acting) to take, at what time, and how long to wait before eating a meal or exercising. I was looking for labs that were digging into molecular mechanisms for how insulin worked. Jesse Roth was the head of the Diabetes Branch at the NIH at the time, and he directed me to various labs at NIH. I was captivated by the lab of Sam Cushman and Les Salans, who were studying glucose transport into cells.

None of the glucose transporters had been cloned at that time, so we studied glucose transporters by cytochalasin B binding to subcellular membrane fractions. We were binding unknown proteins that transported glucose and looking at their movement within the cell. Larry Wardzala, a postdoc in the lab, had shown that insulin caused these glucose transporter proteins to move from intracellular vesicles to the cell surface. I was determined to understand how glucose transport got disrupted in insulin-resistant states and how changes in glucose transporters might contribute to the risk for, or severity of, diabetes.

When I went into the lab at the NIH, I felt a bit like a fish out of water. I had developed a certain amount of expertise in clinical medicine, and here I was starting all over again. Once I gained momentum in the lab, I decided to also do the clinical endocrine fellowship at the NIH. I saw some really fascinating and unusual medical cases, as almost all the patients were on some experimental study protocol. Once I was back into clinical medicine, I realized I wanted to be at an academic medical center. I wanted to be involved in taking care of patients, teaching medical students, and doing research. At that time, Jeff Flier, who was at Beth Israel Hospital and Harvard, was completing a sabbatical in the lab of Harvey Lodish at MIT where the first facilitated diffusion glucose transporter had been cloned. Jeff was looking for a junior faculty member who had expertise in the cell biology of glucose transport. So I ended up at Harvard and Beth Israel Deaconess Medical Center and have never left.

JCI: At Harvard, you've unraveled the roles of GLUT4, RBP4, AMP kinase, and more recently, a new class of lipids. What's to come in the next ten years of the Kahn lab?

Kahn: I've never felt more strongly that I would really love to see our discoveries translated into clinical practice. Specifically, I would like to test whether the novel lipids that my lab discovered with Alan Saghatelian's lab, the branched fatty acid hydroxy fatty acids, will have therapeutic effects for diabetes or immune-mediated diseases in people. Our latest paper that just came out in JCI demonstrates these lipids markedly reduce the incidence of type I diabetes (in mice) and protect human pancreatic $\beta$ cells. It would set the field ahead if we could try these lipids to prevent or treat human disease.

JCI: If you could not be a physician or a scientist, what other vocation do you think could have kept you engaged over a lifetime?

Kahn: I really can't imagine being anything other than a physician-scientist.

\section{Ushma S. Neill,} JCI Editor at Large 